\title{
TRANSFORMAÇÕES NA SOCIEDADE, TRANSFORMAÇÕES NA EDUCAÇÃO: O PROJ ETO CATÓLICO-CONSERVADOR DE EDUCAÇÃO NA DÉCADA DE 1920
}

\section{Society transformations, education transformations: the catholic-conservative project of the education on the decade of} 1920

\author{
Volnei Antonio Sacardo*
}

\begin{abstract}
RESUMO
Em pleno início do século XXI, a educação brasileira persiste na centralidade das preocupações nacionais, evidenciada pela degradação do sistema de ensino e pelas últimas posições que o Brasil ocupa em praticamente todas as análises a que é submetido. Há de se destacar que as mais curiosas propostas aparecem como solução definitiva do problema do ensino brasileiro, típicas, na história do Brasil, de momentos de agitação e transformações em outras esferas sociais. Na perspectiva da "situação de crise" da educação, estimulada pelas transformações de outras áreas, esse artigo procura revelar um importante momento da trajetória educacional no Brasil: a década de 1920, quando a temática educacional se levantava como o centro das discussões nacionais, combinada com o contexto do final da Primeira República. Nesse período, a iniciativa católica, centralizada em Jackson de Figueiredo, apoiava-se na educação para realizar o seu programa de desaceleração da história. Objetiva-se entender o uso da educação para a defesa do ideal Católico-Conservador, em nome da ordem e da formação da elite intelectual católica que, por meio do ensino superior, buscou sistematizar e unir os esforços reacionários enfrentando abertamente a gama de transformações que se operava em diversos setores sociais naquele momento.
\end{abstract}

Palavras-Chave: Educação; conservadorismo; ordem; Jackson de Figueiredo; transformações sociais.

\begin{abstract}
On the XXI century the Brazilian education persists in centralization of national concerns, conspicuous for degradation of the teaching system and for the last positions that Brazil places in practically all analysis, which it is subjected. There's something to detach that the most curious proposals appear as a definite solution of the Brazilian education problem, typical, in the history of Brazil, of agitation moments and transformations in other social globes. On the perspective of the education " crisis situation", stimulated for the other areas transformations, this article tries to reveal an important moment of the Brazilian educational trajectory: the decade of 1920, when the educational thematic stands as the center of the national discussions, combined with the final context of the First Republic. During this term, the catholic initiative, centralized in Jackson de Figueiredo, rested on the education to realize its deceleration program of the history. The target is to understand the use of education to defend of the Conservative-Catholic ideal, on behalf of the order and of the catholic intellectual elite formation that, through superior teaching, looked for systematize and unite the diehards, freely facing the transformations gamma that operated in several social sectors that moment.
\end{abstract}

Keywords: Education; conservatism; order; Jackson de Figueiredo; social transformations.

\footnotetext{
Aluno do curso de Pós-Graduação em Geografia UNESP - Rio Claro. E-mail: fsacardo@yahoo.com.br / Fone: (19) 3406-7350. Endereço: Rua Equador, 244 - Bairro Frezarin - CEP 13465-791- Americana/SP
} 


\section{RESUMEN}

Al inicio del siglo XXI la educación brasileña persiste en la centralización de las preocupaciones nacionales, marcada por la degradación del sistema de enseñanza y por las últimas posiciones que Brasil ocupa practicamente em todos los análisis em los que es sometido. Se puede destacar que las más curiosas propuestas aparecen como solución definitiva del problema de la enseñanza brasileña, típicas, en la historia de Brasil, de momentos de agitación y transformaciones en otras esferas sociales. En la perspectiva de "situación de crisis" de la educación, estimulada por lãs tranformaciones de otras áreas, esse artículo tiene como objetivo revelar um momento importante de la trayectoria educacional em Brasil: la década de 1920, cuando la temática educacional se levantaba como el centro de las discusiones nacionales, ajustada com el contexto del final de la Primera República. En esse período, la iniciativa católica, centralizada em Jackson de Figueiredo, se apoyaba em la educación para realizar su programa de desaceleración de la historia. Se objetiva entender el uso de la educación para la defensa del ideal católico conservador, em nombre del ordem y de la formación da la elite intelectual católica, que, através de la enseñanza superior, buscó sistematizar y unir los esfuerzos reaccionarios, abalanzando abertamente la gama de transformaciones que se operaba y diversos sectores sociales em aquel momento.

Palabras-Clave: Educación; conservadorismo; el orden; Jackson de Figueiredo; transformaciones sociales.

\section{Introdução}

Sob a égide da tecnologia, em pleno início do século XXI, os impressionantes avanços na economia e na ciência não combinam com os problemas elementares que persistem $e$ corroem a base da sociedade brasileira, destruindo as possibilidades de equilíbrio e de avanço em direção às garantias da distribuição das conquistas de diversos setores. Problemas básicos da população, como fome, doenças e geração de renda, reapareceram em proporções nunca antes imagináveis. Nesse quadro contraditório que mistura o sucesso econômico e científico com o fracasso social, a qualidade da educação é apontada como responsável pelos fracassos sociais do mundo contemporâneo. Tal entendimento origina-se dos sistemas de avaliação nacionais $e$ internacionais que submetem o Brasil a processos, mais ou menos rigorosos, de apontamento do seu fracasso, revelado pela degradação do sistema de ensino e pelas últimas posições que ocupa em praticamente todas as análises, além da constatação prática de quem convive diretamente com o sistema de ensino no Brasil.

Há de se destacar que as mais curiosas propostas aparecem como solução definiti- va do problema educacional brasileiro, perpassando pela resolução das dificuldades financeiras, como a construção de novas escolas, maior destinação de verbas ao ensino público, reformas de currículos, mudanças no processo de acesso ao ensino superior e a inclusão de outras formas de entendimento do mundo, não derivadas do método científico, como o Criacionismo. Essa esquizofrenia de propostas no apontamento de caminhos, adoção de novos métodos e/ou abandono completo de outros, tidos como ultrapassados, é típica, na história do Brasil, de momentos de agitação e transformações em outras esferas sociais.

Sobre a educação recai historicamente a responsabilidade pelo destino do país, tornando-se continuamente subterfúgio do fracasso de outros atores da sociedade. A diversidade de propostas oriundas desses momentos de aprofundamento da "situação de crise" na educação brasileira, da mesma forma que possibilita a sua melhoria pela abertura do leque de discussões, também oportuniza o aprofundamento do fosso que separa o lugar o qual deveria ocupar daquele que realmente ocupa. Isto deve-se, principalmente, por ter se transformado em instrumento de pregação ideológica de aventureiros revestidos pelos nobres ideais educativos, mas conservam em seu núcleo ob- 
jetivos de favorecimento político individual, de classe ou de seus fragmentos.

Esse artigo pretende discutir, dentro da perspectiva acima apontada, outro momento da história brasileira em que eclodiam propostas diversas para a educação: trata-se da década de 1920, quando a temática educacional era bombardeada por outros interesses, como o político-partidário, religioso, econômico e social, reduzindo-a a simples instrumento de realização de programas, distantes, na maioria das vezes, das verdadeiras questões pedagógicas. Para tanto, procurar-se-á discutir a iniciativa católica a partir do pensamento de Jackson de Figueiredo e do grupo de intelectuais formado em torno dele em 1922, por meio da criação do Centro Dom Vital e de seu principal órgão de divulgação, a Revista A Ordem, criada em 1921.

\section{As Transformações na década de 1920}

Apesar das reformas culturais empreendidas pela vinda da família real para o Brasil, como a criação da Imprensa Régia, da Biblioteca Nacional Pública, do Museu Real, da Academia Real da Marinha, de cursos médicoscirúrgicos, cursos jurídicos, de economia, química e agricultura, a herança educacional do Império para a República é desoladora. Prevaleceu nas últimas décadas do Império, apesar do avanço das ciências e do Positivismo em outras partes do mundo e até mesmo no Brasil, um quadro de desagregação em que inexistia um projeto nacional de educação. $\mathrm{O}$ ato adicional de 1834 descentralizou e educação formal, cabendo ao poder central promover o Ensino Superior e às províncias o Ensino Elementar e Secundário. O fracionamento da educação, o pequeno número de vagas, a falta de um currículo nacional, a atenção ao Ensino Superior em detrimento de outros associados à exclusão da mulher e à falta de professores qualificados, mesmo com a criação de algumas escolas normais a partir de 1835 , mantém apenas $10 \%$ da população em idade escolar matriculada nas escolas primárias (ARANHA,1993, p.193). Nesse estado generalizado de abandono da educação pública, é aberto espaço para a criação de colégios de iniciativa particular, sobretudo católicos, que além da educação pública, onde já exerciam influência na preponderância do ensino doutrinário e moral sobre o científico, aumentam o controle sobre a população também pelas novas escolas particulares. As iniciativas não religiosas também acontecem, porém, com menor relevância no quadro geral no país.

No fim do século XIX, com o advento da República, uma profunda discussão em torno da educação tomou corpo dentro da diversidade de opinião que nesse período emergia no cenário nacional. Três abrangentes correntes de pensamento exerciam influência sobre a educação. O Positivismo, o Liberalismo e a Corrente Católico-Conservadora. Segundo Nagle (1990, p. 262), "o fervor ideológico que se desenvolveu no final do Império só em parte continua depois da instalação do regime republicano". Apesar de alguns planos como a Reforma Benjamim Constant (1890) e a Caetano de Campos (1892) em São Paulo, acontece, nas primeiras décadas do novo regime um arrefecimento do caloroso debate em torno da educação que movimentou as últimas décadas do século XIX.

Somente após 1915, mais especificamente na década de 1920, o interesse educacional retorna em função do fortalecimento do ideal liberal e das diversas manifestações de contestação da "falsa república". "Trata-se de um movimento de republicanização da República, pela difusão do processo educacional [...]" (NAGLE, 1990, p. 262).

Marcada profundamente pela efervescência social, a década de 1920 representou a agonia do primeiro período republicano, no quadro das profundas mudanças que se operavam no seio da sociedade brasileira. A 
Proclamação da República trouxe poucas novidades práticas para o Brasil, já que até a segunda década do século XX a estrutura social se manteve praticamente inalterada. Nascida do ideal liberal, a expectativa entre as diversas camadas em relação às transformações provenientes da conquista republicana havia sido frustrada, por ter se tornado o reduto da ação das oligarquias rurais, sob comando político dos governadores, e pela manutenção dos privilégios, opostos à natureza de tal movimento. Porém, as velhas resistências do período imperial começaram a ser rompidas definitivamente $e$ uma nova sociedade nasceu de um parto doloroso e da insatisfação com o aprisionamento fetal do corpo que crescia e não cabia mais na bolsa limitada da política, da economia e da antiga sociedade brasileira.

Do ponto de vista econômico, a industrialização se fez de forma balbuciante (SANTOS; SILVEIRA, 2001), mas irredutível quanto à predominância nas décadas que se seguiram estimulada por agentes externos, como a Primeira Guerra Mundial, e internos, como o desenvolvimento de um mercado de consumo $e$ acúmulo de capital, principalmente na região Sudeste. A formação de um mercado interior comandou as importantes transformações que lentamente marcaram a passagem da economia tipicamente feudal para a urbano-industrial.

O crescimento das cidades impulsionou o estilo de vida urbano-industrial que se contrapôs ao rural, agrário e exportador. O novo desenvolvimento econômico não se limitou às transformações quantitativas, provocou mudanças que dialeticamente se combinaram com o novo entusiasmo social e político. Novas camadas e classes refletiam a transição da sociedade imperial, marcada pelas relações escravistas, para uma nova, representada pelo nascimento da classe média, da burguesia industrial e do operariado urbano. Unida ao aparecimento de novas classes, a imigração européia completou o quadro necessário para a agitação social ao trazer para o Brasil idéias e visões de mundo de uma sociedade pioneira na revolução liberal, mais consciente dos direitos trabalhistas e com disposição para participação política. Os efeitos mais notórios da nova realidade transpareceram na agitação grevista, que mesclava o conteúdo emprestado do anarquismo e do socialismo aos grupos insatisfeitos com as novas relações de trabalho e com a condição de atraso do país. Ilustrativo do espírito do momento, o Tenentismo da Revolta do Forte de Copacabana e da Revolução de São Paulo serviu de base para a Coluna Prestes que levou de norte a sul do país o clima de insatisfação.

A estrutura da Política dos Governadores balançou durante a década de 1920. A rigidez e a segurança do revezamento dos dois maiores estados da federação no comando dos rumos nacionais foram afrouxadas pela Reação Republicana e pela Aliança Liberal. Dessa forma, o ideal republicano capenga de 1891 a 1920 ressurgiu e retomou a luta pela representatividade política e garantia dos direitos liberais de igualdade e justiça. Novos partidos e organizações civis, a religião católica e o próprio Estado não passaram à margem dessas transformações.

Diversos setores e fragmentos sociais se envolveram no clima de mudança e a educação passou a ser encarada se não como o mais importante instrumento para o cumprimento dos diversos programas, pelo menos, um dos pontos relevantes para o debate nacional. Segundo Nagle (1974) as décadas de 1910 e 1920 foram marcadas pelo "entusiasmo pela educação", transformando-a no ponto de convergência dos ideais nacionais, tendo na difusão das escolas pelo país a principal bandeira de combate ao atraso nacional. Em meados da década de 1920, o "entusiasmo pela educação" converteu-se em "otimismo pedagógico", trazendo à tona a discussão qualitativa $e$ as novas exigências estritamente educacionais para combater o atraso nessa área, revelado pela elevada população 
analfabeta do país. Diferentes perspectivas marcaram a passagem da educação residual do Império, altamente elitista e declaradamente legitimadora do statu quo para outras propostas. Essas novas correntes, quando progressistas, revelaram a insatisfação com a manutenção da ordem e quando conservadoras atacaram profundamente o desmantelamento do tradicional sistema social e educativo.

As reformas educacionais são visíveis, nesse período, no estudo das propostas de grupos como a Liga de Defesa Nacional, a Liga Nacionalista de São Paulo, o movimento da Escola Nova, o Partido Democrático Nacional e finalmente, dentre outros, o movimento católico; diferentes nos fins, mas convergentes nos meios. Assim as décadas de 1910, 1920 e 1930 assistiram ao bombardeio da educação como principal responsável pela aceleração ou retorno da história.

Quanto à Constituição de 1891, "[...] a Igreja foi forçada à resignar-se: casamento civil, ensino leigo, secularização dos cemitérios, recusa dos direitos eleitorais aos religiosos ligados por voto de obediência [...]" (ALMEIDA; MOURA, 1990, p. 328). Em termos objetivos, a educação católica é prejudicada com a Proclamação da República, pelo avanço das idéias cientificista e pela reforma curricular, que excluiu da grade, disciplinas como História Sagrada ou de Doutrina Cristã.

Desde a Proclamação da República havia uma situação de "calmaria" nos meios leigos e clericais, manifestado pelo distanciamento religioso do cenário político nacional a partir do afastamento entre religião e Estado. Quanto aos efeitos para a Igreja Católica de tal separação, duas formas de análise podem ser encontradas. A primeira a entende como negativa, pois decorreu desse evento o enfraquecimento da religião, dependente historicamente da proteção oficial e do privilégio garantido pelo poder público, sob a forma de padroado. A segunda compreende o evento de
1891, como favorável pelo rompimento positivo, portanto, com o subjugamento e o papel secundário desempenhado pela religião nos últimos anos do império.

Independente de tais formulações, a década de 1920 significou o rompimento com a "mornalidade" católica pela organização do movimento leigo, coordenado por Jackson de Figueiredo, sob orientação de Dom Sebastião Leme, que desde 1916 havia estremecido a passividade católica com a elaboração da $1^{a}$ Carta Pastoral, na qual conclamava os católicos a desempenharem um papel político ativo, como forma de revalorização dos ideais cristãos esquecidos pela maioria da população que se autodefinia católica. A reação conservadora foi estruturada tendo como pano de fundo as transformações sociais, econômicas e políticas, atingida portanto, pela base de toda a sua estrutura e lógica interna de pensamento, não se reduzindo meramente à ambição de sua presença no novo regime. Dessa forma, se opôs à gama de transformações de todos os aspectos da vida social, constituindo-se como pensamento e ação conservadora/reacionária via educação.

Para entender a posição jacksoniana, portanto católica, diante da educação na década de 1920, é necessário entender a significação do termo conservador. O termo conservador teve origem no Iluminismo do século XVIII, cujos representantes acusavam-no de contraposição injustificada às ideais naturalistas, materialistas e do progresso inevitável (VIEIRA, 1998). O conflito entre as idéias iluministas e o pensamento conservador centrava-se na oposição entre igualdade/liberdade de um lado e manutenção da hierarquia/ vida regrada pela Igreja de outro. Defensor do pensamento católico, Jackson de Figueiredo era crente de verdades eternas e absolutas, do predomínio do poder divino em relação ao temporal. No bojo desse movimento de oposição entre novo e tradicional, centrou o seu combate.

Parte das justificativas do seu pensamento veio das leituras de Joseph De Maistre, 
expositor do pensamento autoritário, antiprogressista, antimaterialista $e$ antidemocrático. Italiano, formado em direito em 1772. Crítico da Revolução Francesa, De Maistre lutou arduamente pelo retorno à monarquia tradicional. Uma das suas principais obras: "Considerações sobre a França", de 1797, representou um marco para o pensamento Conservador. Suas idéias se resumem na negação das transformações daquela que deveria ser a autoritária, conservadora e rígida organização social. Segundo De Maistre (apud VIEIRA, 1998, p. 31), "os homens veneram o que não podem compreender. As sociedades devem ser governadas pelos costumes e pelas instituições, cuja origem se perde nas névoas da história". Tal Conservadorismo está intimamente relacionado ao momento, ao local e a forma como ocorre e se traduz pela posição de defesa de um conjunto de idéias contrárias às transformações de uma determinada realidade. Dessa forma, a utilização do termo conservador para Jackson de Figueiredo, se refere

Às atitudes e doutrinas conservadoras que representam-se em concepções de mundo, em construções ideológicas, em sistema de idéias, cujos significados se enraízam num grupo ou numa classe social, $e$ explicam essas atitudes e essas doutrinas (VIEIRA, 1998, p.30)

A atitude prática de Jackson de Figueiredo, sergipano de Aracaju, advogado empenhado na causa católica, se fez pela criação do Centro Dom Vital em 1922, onde formou um grupo de intelectuais católicos que desempenhou importante papel. Além da transformação das consciências e a publicação da Revista A Ordem, criada em 1921, destacou-se pelos embates travados nos órgãos públicos de representação, em jornais e revistas.

O projeto de educação defendido por Jackson de Figueiredo e, conseqüentemente, pelo grupo de intelectuais formado em seu entorno fez-se em consonância com a visão católica de sociedade e das transformações que nela se operavam. O desenvolvimento econômico, nessa visão, era atacado por permitir as mudanças de posição de grupos ou indivíduos na hierarquia social, entendida como imutável e necessária para a manutenção da ordem. Quanto ao Estado, Jackson de Figueiredo defendia o governo autoritário e centralizado; representante temporal da ordem, submisso à Igreja - verdadeira e única representante do poder divino.

Das mudanças sociais, criticava duramente os novos costumes, a imigração para as cidades e os movimentos revolucionários, tais como os movimentos tenentistas e as greves que passaram a ocorrer com freqüência após 1917. Considerava a revolução social um mal, movimento satânico de desagregação, derivada de um povo deseducado e de um ambiente permissivo e favorável à agitação e desarticulação política e social. Sua posição se fazia contra os ideais liberais, o Socialismo e o Anarquismo. Seguramente Jackson de Figueiredo se enquadrou no movimento de intelectuais do século XX que assumem a política como centralidade de suas elaborações convergindo diversas correntes em torno do ideal de que o Estado responderia ao problema da organização do poder, que naquele momento adquiria proporção nacional.

Segundo Pecault, "O processo de conversão dos intelectuais em agentes políticos assumiu, a partir de 1915 o caráter de um movimento global e realizou-se sobre diversas formas: vaga nacionalista, modernização cultural, ressurgimento católico e impulso antiliberal" (PECAULT, 1990, p. 23). O contexto da República Velha em que a totalidade das classes sociais ainda não apresentavam uma situação de estabilidade e que a política tramitava entre o avanço liberal e a decepção $e$ inconformação republicana exigiu de Jackson de Figueiredo dois papéis a priori distintos e antagônicos, mas que na complexidade do momento se explicam e completam. Se por um lado temia o futuro que 
despontava, por outro, rejeitava o presente. Defendia como exemplo de sociedade a Idade Média, onde os valores católicos garantiriam a ordem e o respeito à autoridade. A reconstrução desse momento da história só poderia acontecer pela educação, vista como transformadora das consciências e, portanto, meio pacífico $e$ espiritual de revolução $e$ formação da elite intelectual católica que conduziria as mentes ao desenvolvimento do verdadeiro projeto nacional. A exemplo do que acontecia com outras organizações do período, a discussão sobre a educação passou distante dos reais problemas pedagógicos.

Para os católicos só havia uma opção para a recuperação da sociedade: a compreensão e a incorporação das leis divinas e sobrenaturais provenientes de Deus. No contexto da segunda década do século XX, devido à aceleração das transformações e à efervescência do período, a incorporação das leis divinas correspondia à única possibilidade de enfrentamento do mobilismo moderno e do avanço positivista. Esse pensamento também pode ser tratado como tradicionalista, por buscar na tradição brasileira a saída do caos social.

A viabilidade do resgate do tradicionalismo e da ordem perpassa pela construção de uma elite intelectual católica que conduziria à restauração da ordem nos padrões medievais. Para Jackson de Figueiredo, a República, representou a traição de um pequeno grupo movido pelo espírito moderno, ao tirar Deus da constituição, vetar a obrigatoriedade do ensino religioso e criar o ambiente de desordem política e social. A constituição da República não somente traiu o ideal católico como a própria nacionalidade, pois se existia uma verdadeira tradição no Brasil, essa é a tradição católica. Da sua reconstrução depende a existência do verdadeiro nacionalismo, entendida por Jackson de Figueiredo como
[...] ação de uma elite que, acertada ou erroneamente, repito, mas de boa fé, quer dar a uma dada pátria o sentimento e a idéia de que já a constitui uma raça histórica, tão legítima quanto as que mais legítimas se julguem (FIGUEIREDO, 1921, p. 22).

Portanto, o afastamento de Deus da constituição não foi apenas um atentado contra a Igreja, mas contra a nacionalidade. Dependia da elite intelectual católica a reconstrução da ordem e da nacionalidade, cabendo à educação a sua formação, responsabilizando-a pelo destino moral e social do país. Coerente com a forma católica de organização social, a educação não deveria trilhar os caminhos da democracia, mas negá-la duplamente: primeiro por não divulgar os avanços ou conquistas do pensamento científico e segundo porque não vislumbrava a inclusão das massas no processo educativo. Combina-se perfeitamente a defesa da educação elitista com o autoritarismo católico. Dois projetos de educação partiam do grupo católico: um para o ensino primário e outro para o superior. A preocupação e as esperanças de Jackson de Figueiredo em recatolicizar o país derivava-se da escola superior, acreditava que a fé católica viria pela revelação, por meio do ensino da filosofia tomista. À educação primária cabia o ensino pela repetição dos valores morais e do resgate da tradição.

A educação, para os católicos, era dever da Igreja e da família. A concepção restringia-se a participação do Estado republicano, travando o embate entre o grupo católico e os escolanovistas: pela defesa do papel da educação, obrigatoriedade do ensino primário, método e a responsabilidade de tal processo. Para os católicos, a Igreja deveria ser a "Grande Mestra", responsável pela condução da educação, 
por possuir o direito divino - sobrenatural, na orientação das consciências. À família cabia o direito natural de educar, pois antes de pertencer à sociedade, o homem pertence ao núcleo familiar, primeira organização social. Ao Estado cabe o papel secundário, restrito à construção de ferramentas que garantam a execução do processo educativo definido pela Igreja. $\mathrm{Da}$ condução católica do ensino superior nasceria a elite católica, enquanto que o acesso ao primário seria restrito, pois a massa da população deveria ser conduzida e, para tanto, a ignorância era uma santa alternativa aos espíritos rebeldes modernizantes.

Nessa perspectiva, a educação laica representa uma profunda ameaça à ordem e à sociedade por ser local da pregação da liberdade, naturalmente repaganizadora. Deve-se à escola a restituição da autoridade, da unidade, do respeito à propriedade e à família, orientada pelos princípios infalíveis da religião católica. A educação católica se contrapôs substancialmente aos demais movimentos da educação por não pretender o progresso e nem vislumbrar modelos externos para o Brasil, como o dos países europeus. Jackson acreditava que as soluções dos problemas brasileiros existiam internamente, dependiam simplesmente do resgate da tradição. A educação assumia o papel político, para aplicação das soluções morais e materiais, já resolvidas desde a Idade Média. À educação iniciada na família, se seguiria a escolar, privilegiada por marcar a transição da esfera particular à pública, revestida do sentido de ação católica. Pela recuperação da filosofia e do conhecimento dos dogmas, o grupo católico pretendia elevar o homem individual à categoria de ser social. Somente pela educação conservadora e reacionária o Brasil poderia ter certeza do futuro, num processo de desaceleração da história.

Em 1926 os intelectuais leigos coordenados por Jackson de Figueiredo e Dom Sebastião Leme lutam para conquistar espaço na re- forma Constitucional de Arthur Bernardes, por meio de duas emendas: a primeira pretendia tornar o Catolicismo como religião oficial e a segunda pretendia o ensino religioso facultativo nas escolas públicas.

Essas exigências tinham como principal argumentação o número de católicos no Brasil. Como grande maioria, os católicos deveriam ter seus direitos respeitados em garantir aos filhos a educação cristã católica e o seu reconhecimento como religião oficial. Sabendo da apatia política dos católicos brasileiros, a educação católica também deveria aquecer a ação dos declarados católicos, que desde o Império dormiam na tranqüilidade da vida cotidiana, admitindo os efeitos maléficos da república na política, do liberalismo na economia e das liberdades e revoltas anárquicas, grevistas e socialistas no campo social. A eclosão da reação católica coincidiu com o aparecimento do movimento escolanovista. Segundo Nagle (1990) o movimento escolanovista no Brasil aconteceu em dois momentos distintos, o primeiro que abrange o fim do Império até o final da segunda década do século XX e o segundo que compreende a década de 1920.

No primeiro momento encontravam-se alguns antecedentes, idéias vagas ou pouco sistematizadas dessa nova concepção de educação. Também aparecem nesse primeiro momento algumas ações práticas como a criação de escolas modelos em São Paulo e o decreto $n^{\circ}$ 980, de 1890, como centro impulsionador da nova forma de concepção de ensino. Não por coincidência, é na década de 1920 que tal movimento se processa, principalmente pelo amplo projeto reformador do sistema de educação. O objetivo principal do escolanovismo se referia à mudança no processo de ensino/aprendizagem. A idéia central era sistematizar e entender cientificamente os diferentes processos de aprendizagem tendo o aluno como centro da educação. 
Nesse momento o "entusiasmo pela educação" abre espaço para "otimismo pedagógico", ou seja, a educação deixa de ser o meio de atender objetivos e programas políticos para se tornar o núcleo de preocupações internas relacionadas à aprendizagem. A preocupação com a função social da escola para a vida do aluno, a organização do currículo voltado para a realidade do educando, a infância vislumbrada como um momento importante da vida e a democratização da educação primária como princípio da liberdade se opunham substancialmente ao projeto de educação de Jackson de Figueiredo. Para esse, a educação também tinha um papel social, que deveria se estruturar em torno da manutenção da ordem. A ordem para o pensamento conservador era expressão clara do predomínio da hierarquia. À educação cabia o papel de controlar e frear os espíritos rebeldes, principalmente pelo ensino da religião. A doutrina católica teria na escola a continuidade da religião. Como os Jesuítas atuavam na conversão dos povos, também a Igreja atuaria, refreando a rebeldia das consciências. O mecanismo a seguir compara o projeto de educação de Jackson de Figueiredo e do grupo católico com o ideal escolanovista.

1. QUADRO COMPARATIVO DAS PROPOSTAS EDUCACIONAIS DO MOVIMENTO CATÓLICO-CONSERVADOR E O MOVIMENTO ESCOLANOVISTA

\begin{tabular}{|l|l|}
\hline Proposta educacional escolanovista & Proposta educacional de Jackson de Figueiredo \\
\hline $\begin{array}{l}\text { Ensino Superior como resultado do } \\
\text { desenvolvimento dos outros níveis de } \\
\text { educação }\end{array}$ & $\begin{array}{l}\text { Ensino Superior para a formação da elite } \\
\text { intelectual católica, desvinculado de ou tros níveis } \\
\text { de ensino }\end{array}$ \\
\hline $\begin{array}{l}\text { Atenção ao ensino primário como forma de } \\
\text { democratização do ensino }\end{array}$ & $\begin{array}{l}\text { Ensino primário para domar os espíritos rebeldes: } \\
\text { liberais e anarquistas }\end{array}$ \\
\hline $\begin{array}{l}\text { Método de ensino baseado nas descobertas } \\
\text { científicas do aprendizado por faixas etárias e } \\
\text { do comportamento humano }\end{array}$ & Método de ensino baseado na repetição \\
\hline $\begin{array}{l}\text { Educação como divulgadora das idéias } \\
\text { científicas }\end{array}$ & Educação como divulgadora da doutrina católica \\
\hline Educação para desenvolver a liberdade & Educação para controlar a liberdade \\
\hline \begin{tabular}{l} 
Educação em oposição à ignorância \\
Educação católica em oposição à educação laica. \\
\hline O centro da aprendizagem é o aluno.
\end{tabular} & O centro da aprendizagem é o professor \\
\hline
\end{tabular}

Após a morte prematura de Jackson de Figueiredo em 1928, o movimento pela educação católica passou por uma luta mais ferrenha, tanto pelas mudanças que se operavam no Centro Dom Vital, irradiador monopolizado pelo líder do movimento católico desde 1922, ano de sua fundação, como pelo espaço aberto na política nacional em 1930. Dom Sebastião Leme, Alceu Amoroso Lima - substituto de Jackson de Figueiredo no Centro Dom Vital - e o padre Leonel Franca continuaram o projeto de Jackson de Figueiredo de recristianização católica do país. Mesmo com uma proposta mais cultural do que política, o grupo católico pósJackson não arrefeceu na busca de inclusão do ensino religioso no currículo oficial e na criação de um centro de ensino superior, partindo da derrota de 1926, quando a proposta de ensino religioso facultativo foi rejeitado na emenda constitucional, para a primeira conquista real 
nesse campo. Já em 1931, com a promulgação do decreto 19941 de 30 de abril, tornou-se facultativo o ensino religioso nas escolas públicas.

O governo de Getúlio Vargas não tardou em perceber a importância do ideal católico no combate ao comunismo e aos movimentos sociais, permitindo a aproximação do ideal católico do poder oficialmente constituído. Tal representação se confirma com a constituição de 1934, quando a Igreja quase recupera o seu caráter de oficialidade, com a garantia de não legalização do divórcio e o retorno do ensino religioso facultativo nas escolas públicas, agora, garantido constitucionalmente.

Desde 1929, o Centro Dom Vital, sob comando de Alceu Amoroso Lima, expandiu sua atuação através da Ação Católica, mais importante organização laica católica do Brasil. Um dos importantes instrumentos de formação intelectual superior foi a criação da Associação Universitária Católica, que passou a usufruir espaço próprio na Revista A Ordem. Em 1932, a criação do Instituto Católico de Estudos Superiores e a sistematização do ensino católico na área superior revelavam a intenção de controlar a educação superior. Em 1941 entram em funcionamento no Rio de Janeiro os dois primeiros cursos superiores controlados pela Igreja Católica, de Direito e Filosofia. Em 1946, devido à junção com a Escola de Serviço Social do Instituto Social do Rio de Janeiro, fundada em 1937, forma-se a Universidade Católica, agraciada em 1948, pela Santa Sé, ao receber as prerrogativas de Pontifícia Universidade Católica.

\section{Conclusão}

Quanto à correspondência entre o ideal sonhado por Jackson de Figueiredo e a educação como bandeira para a sua realização, pode- se afirmar que pouco se realizou do ambicioso projeto católico. A idéia de transformar o país em reduto da ordem, com retorno da história $e$ resgate do tradicionalismo católico em nome da nacionalidade, efetivamente não se realizou.

É evidente que o pensamento Católico-Conservador firmou-se pela sistematização e atuação política leiga dos católicos organizados. Ainda que diluída em manifestações atuais, resistentes às transformações no ramo científico, como a discussão em torno das células-tronco e da clonagem, em luta constante pelo espaço político e pela relevância de sua representatividade $e$ inflexibilidade quanto ao controle de natalidade, a história desse movimento no Brasil comprovou não ser a educação o reduto da realização do programa católico. Com universidades próprias, organizadas pelos mais responsáveis e apaixonados católicos, atuantes intensos na área política e cultural, o pensamento Conservador protagonizado por Jackson de Figueiredo, apesar das transformações nos objetivos iniciais e das relativas conquistas, deixa uma importante lição para as especulações em torno dos projetos educacionais: a educação não é a única responsável pelos rumos do país, devedora dos encargos decorrentes dos fracassos de todos os demais setores. No sentido Freireano, a educação é participante da transformação social, porém responsabilizá-la ou sobrecarregá-la pelos fracassos ou sucessos do complexo sistema histórico-social do país, demonstrado, pelo exemplo católico, é ingenuidade. As preocupações que atualmente devem ser mantidas com a educação não podem destoar das mantidas com outras organizações, como a polícia, o poder público, a família, o sistema de saúde etc.

Percebe-se, claramente, que as escolas públicas e privadas estão sobrecarregadas pelo seu trabalho, que não é pouco, e por funções delegadas por outros setores da sociedade. O avanço da educação brasileira depende do tratamento estritamente pedagógico dispensado ao seu dinamismo interno, partindo do 
movimento de mundo para a formação de alunos aprendentes e atuantes, lembrando que a construção do conhecimento é ao mesmo tempo difícil e imprescindivel para a formação humana. Qualquer iniciativa que busque a educação como realização de objetivos individuais alheios às necessidades pedagógicas, colaborará decisivamente para o fracasso do cumprimento de seus programas e o que é ainda pior: marcará negativamente a educação, servindo menos para a melhoria e o desenvolvimento da sociedade.

A partir desse breve relato histórico, algumas reflexões podem ser sugeridas. A priori, a comparação entre esses dois períodos é possível porque a evolução do quadro econômico e a retração das políticas sociais, na década de 1920 marcada pelo elitismo da política dos governadores e atualmente pelo Neoliberalismo, apontam para resultados iguais, sendo que depois de quase 90 anos os desafios na educação brasileira continuam no centro da discussão nacional.

O apelo de grupos exteriores à esfera educacional, a exemplo do católico na década de 1920, expressa a semelhança entre esses dois momentos. As religióes ainda resistem aos avanços da ciência. Num momento em que se luta pela superação de problemas históricos no campo da vida - como a cura de doenças a partir da manipulação genética e de antídotos para enfermidades que ainda afligem a humanidade - os quais tiveram na educação o desenvolvimento e a possibilidade de avanço, ainda existem grupos defendendo o retorno do Criacionismo como meio de entendimento do universo.

Em 09/03/2008, a Igreja Católica divulgou os novos pecados, onde se destaca juntamente com o uso de drogas, poluição ambiental e desigualdade social, a manipulação genética. Excluindo os três primeiros, abstratos e de difícil apontamento e identificação dos responsáveis, o golpe mais duro para o "mundo moderno", para a melhoria da sociedade e o conjunto da humanidade está vinculado ao combate declarado ao avanço da ciência, ou seja, à própria educação. Somado à questão do aborto, do controle de natalidade e questões de saúde pública, a Igreja Católica mantém institucionalmente a posição conservadora do início do século passado, de manutenção da ordem e de ataque às conquistas modernas.

Multiplicado pela geração de seitas, religiões e formas mágico-religiosas de explicação da realidade, o arrebanhamento de novos adeptos tem encontrado na dificuldade de acesso da maioria das pessoas aos avanços da ciência o campo fértil do qual se colhe números surpreendentes para o crescimento da ideologia anti-científica. A educação não passa à margem de tais retrocessos. Quando não é incorporada ao currículo ou à práticas conservadoras, a influência negativa da religião aparece no duro embate que a escola progressista trava com valores morais e antiquados da sociedade do início do século XXI. Ultrapassando tais limites para a análise, é impressionante como a educação se tornou depositária das mais diversas propostas. A confluência da escola com a ciência pode transformar esse momento de revigoramento do "entusiasmo pela educação" em bens reais e concretos, numa passagem de projeto de escala pessoal ou elitista para a coletividade social, com benefício à coletividade. Quando a escola estiver livre de projeto de outros atores, que ancoram o vazio de suas áreas na educação, e puder se entregar à nova tarefa de incorporação da ciência em seus métodos, na divulgação e no desenvolvimento científico, a humanidade terá acesso às melhorias modernas, ocupando o espaço de outros programas extra-científicos que historicamente marcaram os mais horrendos capítulos da miserável história humana. 


\section{REFERÊNCIAS}

ALMEIDA, José M. G; MOURA, Sérgio L. A Igreja na Primeira República. In: Fausto, B. (org). O Brasil Republicano. t. 1, v.2, São Paulo: DIFEL, 1990.

ARANHA, Maria L. A. História da Educação. São Paulo: Moderna, 1993.

FIGUEIREDO, Jackson de. Do Nacionalismo na hora presente. Rio de Janeiro: Centro Dom Vital, 1921.

NAGLE, Jorge. Educação e sociedade na Primeira República. São Paulo: EPU/EDUSP, 1974.
NAGLE, Jorge. A educação na Primeira República. In: Fausto, B. (org). O Brasil Republicano. t. 1, v.2, São Paulo: DIFEL, 1990.

PECAULT, Daniel. Os intelectuais e a politica no Brasil: entre o Povo e a Nação. São Paulo, Ática, 1990.

SANTOS, Milton; SILVEIRA, Maria Laura. O Brasil: território e sociedade no início do século XXI. Rio de Janeiro: Record, 2001.

VIEIRA, Evaldo. Poder político e resistência cultural. Campinas/SP: Autores Associados, 1998.

Texto recebido em 19 fev. 2008. Texto aprovado em 13 mar. 2008. 